\title{
Pnictogen-Bonding Catalysis and Transport Combined: Polyether Transporters Made In Situ
}

\author{
Heorhii V. Humeniuk, ${ }^{\dagger}$ Andrea Gini, ${ }^{\dagger}$ Xiaoyu Hao, Filipe Coelho, Naomi Sakai, and Stefan Matile*
}

Cite This: JACS Au 2021, 1, 1588-1593

Read Online

ABSTRACT: The combination of catalysis and transport across lipid bilayer membranes promises directional access to a solventfree and structured nanospace that could accelerate, modulate, and, at best, enable new chemical reactions. To elaborate on these expectations, anion transport and catalysis with pnictogen and tetrel bonds are combined with polyether cascade cyclizations into bioinspired cation transporters. Characterized separately, synergistic anion and cation transporters of very high activity are identified. Combined for catalysis in membranes, cascade cyclizations are found to occur with a formal rate enhancement

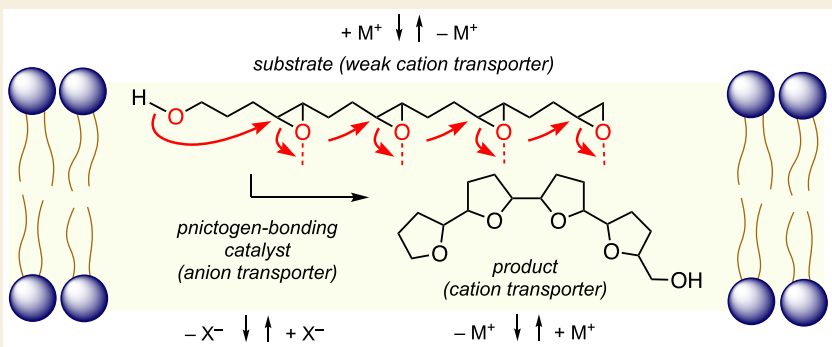
beyond one million compared to bulk solution and product formation is detected in situ as an increase in transport activity. With this operational system in place, intriguing perspectives open up to exploit all aspects of this unique nanospace for important chemical transformations.

KEYWORDS: Ion transport, catalysis, pnictogen bonds, polyethers, cascade cyclizations

$\mathrm{R}$ eactions that occur in lipid bilayer membranes continue to fascinate us, from early oscillating oxidations, ${ }^{1}$ selfreplicating vesicles, ${ }^{2}$ templated polymerizations, ${ }^{3-5}$ photoredox processes, $^{6-9}$ and catalytic pores ${ }^{10}$ to more recent dynamic covalent chemistry, ${ }^{11,12}$ molecular rockets, ${ }^{13}$ multistep cascades, ${ }^{14,15}$ and signal transduction systems. ${ }^{16-18}$ The direct combination of reactions with transmembrane transport has received less attention. The most developed systems operate with existing biological protein architectures, ${ }^{19}$ thus avoiding synthetic efforts and direct participation of the membrane in the process. However, the coupling of catalysis and transport appears promising for several reasons in addition to the obvious unique detectability. Most importantly, lipid bilayer membranes offer a solvent-free environment that should strengthen noncovalent interactions. This removal of the often undesired contributions of solvents to catalysis is reminiscent of transformations in the gas phase or in silico. The volume provided for these solvent-free reactions is small and structured: A confined nanospace that appears ideal to maximize effective concentrations and control selectivity. Moreover, the combination of catalysis with transport adds directionality along a polarity gradient, promising remote control over diffusion ${ }^{20-23}$ along changing environments to maximize transition-state stabilization, minimize product inhibition, vary selectivity, and so on. Compartmentalization further invites multistep processes ${ }^{6-10,14,15}$ and various forms of detection. ${ }^{10,19}$ Taken together, these intriguing characteristics promise access to rate enhancements, new selectivity, and, at best, new reactivity. To thus explore the possible combination of catalysis and ion transport within lipid bilayer membranes, we decided to couple two topics of current concern, that is, transport and catalysis with chalcogen, pnictogen, and tetrel bonds and the biomimetic epoxideopening cascade cyclizations into polyether cation transporters (graphical abstract).

Anion transport ${ }^{24-37}$ with pnictogen bonds ${ }^{38-44}$ has been realized recently ${ }^{31-33}$ as logical continuation of the earlier studies with chalcogen ${ }^{34,35}$ and halogen ${ }^{36,37}$ bonds. These unorthodox interactions all originate from $\sigma$ holes and, related to $\sigma^{*}$ antibonding orbitals, extend linearly from all covalent bonds made by the element (Figure 1a, see refs 44 and 38 for electrostatic potential surfaces). ${ }^{45-56}$ Their strength increases with withdrawing substituents and polarizability of the element, that increases top-down and right-left in the periodic table. $^{31}$

Fluorophenyl derivatives $\mathbf{1 - 1 2}$ were considered to act as both anion transporters and catalysts. They were prepared following reported procedures (Scheme S1). ${ }^{31,44}$ Ion transport was measured in EYPC LUVs with the classical HPTS assay. ${ }^{57,58}$ In this assay, EYPC LUVs (egg yolk phosphatidylcholine large unilamellar vesicles) are prepared with entrapped HPTS, a pH-sensitive fluorophore. Then the

Received: August 10, 2021

Published: September 28, 2021 


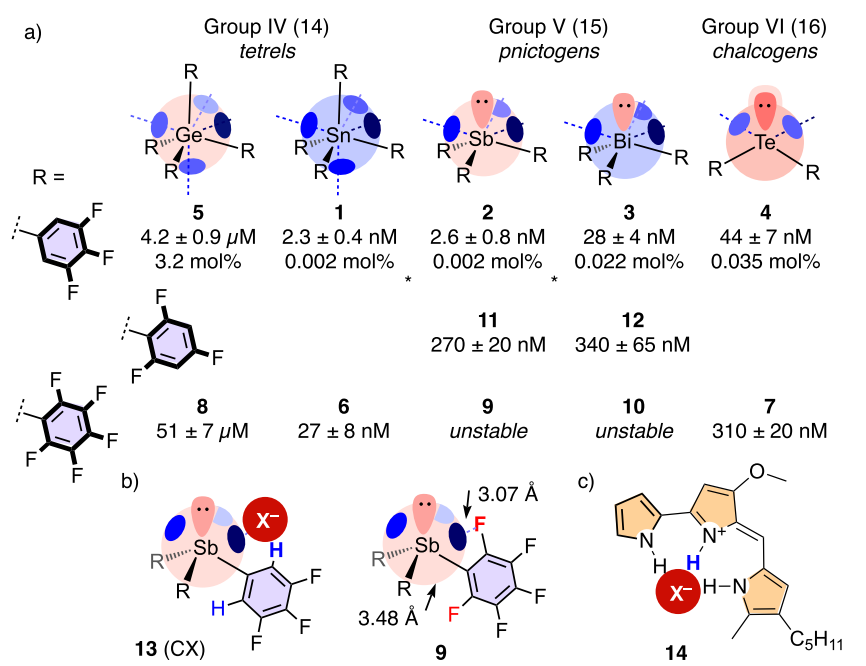

Figure 1. (a) Structure and anion transport activity of catalyst candidates 1-12, with $\mathrm{EC}_{50}$ values in absolute concentrations and mol\% relative to EYPC (HPTS assay, EYPC LUVs in buffer containing $\mathrm{NaCl}$ ). (b) $\mathrm{CX}$ complex 13 and $\mathrm{F}-\mathrm{Sb}$ distances in the $\mathrm{X}$-ray structure of 9. (c) $\mathrm{HX}$ prodigiosin complex. Blue ellipses indicate $\sigma$ holes.

transporter is added, followed by a base pulse (or vice versa). The dissipation of the resulting $\mathrm{pH}$ gradient is then followed by ratiometric changes in HPTS fluorescence, reporting on $\mathrm{OH}^{-}$/anion and $\mathrm{H}^{+}$/cation antiport and on $\mathrm{OH}^{-} / \mathrm{M}^{+}$and $\mathrm{H}^{+}$/ $\mathrm{X}^{-}$symport. At the end of the experiment, an excess of channel forming peptide gramicidin $\mathrm{D}$ is added to determine maximal fluorescence intensity for calibration. Results are summarized in dose-response curves (DRCs) and reported as $\mathrm{EC}_{50}$, the effective transporter concentration needed to reach $50 \%$ activity.

According to the HPTS assay, the most active anion transporters were $\sigma$-hole donors $1-4$ equipped with 3,4,5trifluorophenyl $\left(\mathrm{FP}_{345}\right)$ substituents (Figure 1a). Anion transport with tetrel bonds as in stannane $\mathbf{1}$ is novel in this series, and activities were with $\mathrm{EC}_{50}=2.3 \pm 0.4 \mathrm{nM}$, very high (Figure S6). Tris (3,4,5-trifluorophenyl)stibine $\left(\mathrm{Sb}\left(\mathrm{FP}_{345}\right)_{3}\right) 2$ was similarly active, while bismuthane 3 was less powerful because, presumably, of the more dominant metallic character. The still high activity of tellane $\mathbf{4}$ followed polarizability trends. An only micromolar $\mathrm{EC}_{50}$ of germane 5 was consistent with the previously described ${ }^{44}$ inaccessibility of the $\sigma$ holes on the too small element.

The $\mathrm{FP}_{2-6}$ series $\mathbf{6}-\mathbf{9}^{31}$ was overall less active compared to 1-5 because intramolecular pnictogen bonding of the ortho fluorines weakens anion binding (Figure $1 \mathrm{a}, \mathrm{b}) .{ }^{44}$ The ortho hydrogens in $\mathrm{FP}_{345} \mathbf{1 - 5}$, in contrast, are repelled by the $\sigma$ holes and can further assist anion binding in the catalyst-anion (CX) complex 13. While $\mathrm{FP}_{2-6} 9$ and 10 were unstable, $\mathrm{FP}_{246}$ analogues 11 and 12 confirmed that ortho fluorines indeed weaken anion transport significantly. $\mathrm{FP}_{246} 11$ and 12 and all other compounds were stable in buffer (Figures S2-S5). This included the best pnictogen-bonding catalyst 2 and marked a clear contrast to ligand-exchanging, water-incompatible general Lewis acid catalysts.

To facilitate comparison, some $\mathrm{EC}_{50}$ 's are also reported in mol\% lipid. Today's record among small molecule transporters is arguably $\mathrm{EC}_{50}=6.1 \times 10^{-5} \mathrm{~mol} \%$ for the tridentate $\mathrm{HX}$ binding natural product prodigiosin 14, closely followed by a multidentate oligo-urea macrocycle. ${ }^{30}$ A 1000 times weaker
$\mathrm{EC}_{50}=0.01 \mathrm{~mol} \%$ has been recently reported for bidentate halogen-bonding transporters as current best in the context of $\sigma$-hole transporters. ${ }^{35}$ The $\mathrm{EC}_{50}=1.8 \times 10^{-3}$ and $2.1 \times 10^{-3}$ mol\% of the monodentate and neutral 1 and 2 , only about 30 times weaker than cation 14, thus confirmed the power of anion transport with the hydrophobic, strong and directional tetrel and pnictogen bonds.

Polyether cascade cyclizations were selected as reactions of choice for this study. Polyethers are among the most popular cation transporters. ${ }^{59-65}$ Examples reach from tetrahydrofuran (THF) oligomers such as the natural product monensin A 15 and early artificial ion channels ${ }^{59}$ to most popular crown ethers $^{60-64}$ and acyclic motifs (Figure 2). ${ }^{64,65}$ In nature,

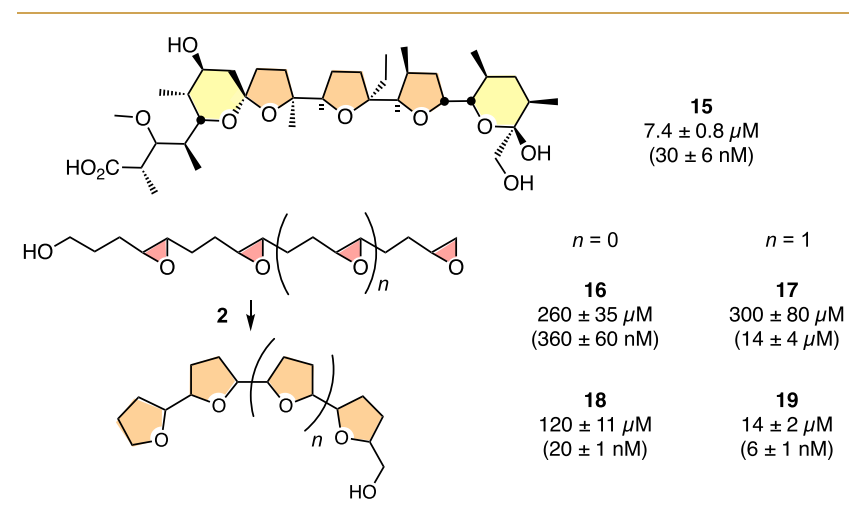

Figure 2. Structure and cation transport activity of substrate and product candidates 16-19 with $\mathrm{EC}_{50}$ values (EYPC LUVs, $\mathrm{NaCl}$ ), compared to monensin A $\mathbf{1 5}$ and the presence of FCCP (in parentheses).

polyether transporters are synthesized by epoxide-opening cascade cyclizations. ${ }^{66-74}$ These charismatic processes have been studied extensively, ${ }^{66-71}$ recently also with anion- $\pi$ catalysis. $^{72-74}$ To further expand the integration of unorthodox interactions, pnictogen-bonding catalysis has been introduced as noncovalent counterpart of Lewis acid catalysis. ${ }^{44}$ Polyether cascade cyclizations have served well to demonstrate that the two are not the same, just like noncovalent hydrogen bonding and covalent Brønsted acid catalysis have their distinct advantages. $^{44}$

Oligo-epoxides 16 and 17 cyclize selectively into 18 and 19, respectively (Figure 2). ${ }^{72}$ The four compounds and their analogues were synthesized following reported procedures (Figure S14). ${ }^{72}$ The transport activity of THF oligomers increased with length as expected, from less active monomers and dimers $\left(\mathrm{EC}_{50}=1.1 \pm 0.4 \mathrm{mM}\right)$ up to tetramer 19 (Figure 2 ). Compared to 19 , monensin A 15 was more active without but less active with the proton carrier FCCP, indicating that 19 is a better sodium transporter and a weaker proton transporter. $^{57,58}$ A previously unexplored family, the oligoepoxides 16 and 17 were identified as weak ion transporters. Multiply methylated analogues were more active $\left(\mathrm{EC}_{50}=8.9 \pm\right.$ $0.7 \mu \mathrm{M}$ for tetramers, Figure S19) but less attractive for catalysis studies because of violations of the Baldwin rules ${ }^{44}$ and relatively high background reaction in water.

Because stannane $\mathbf{1}$ is a weaker catalyst, ${ }^{44}$ anion transporter 2 and cation transporters $\mathbf{1 7}$ and $\mathbf{1 9}$ were selected to combine transport and catalysis (Figure 3). However, the outstanding transport activity of $\mathbf{2}$ prevented access to the high concentrations of substrate and catalyst needed to observe sufficiently fast initial rates for direct detection (Figure $3 b$ ). 


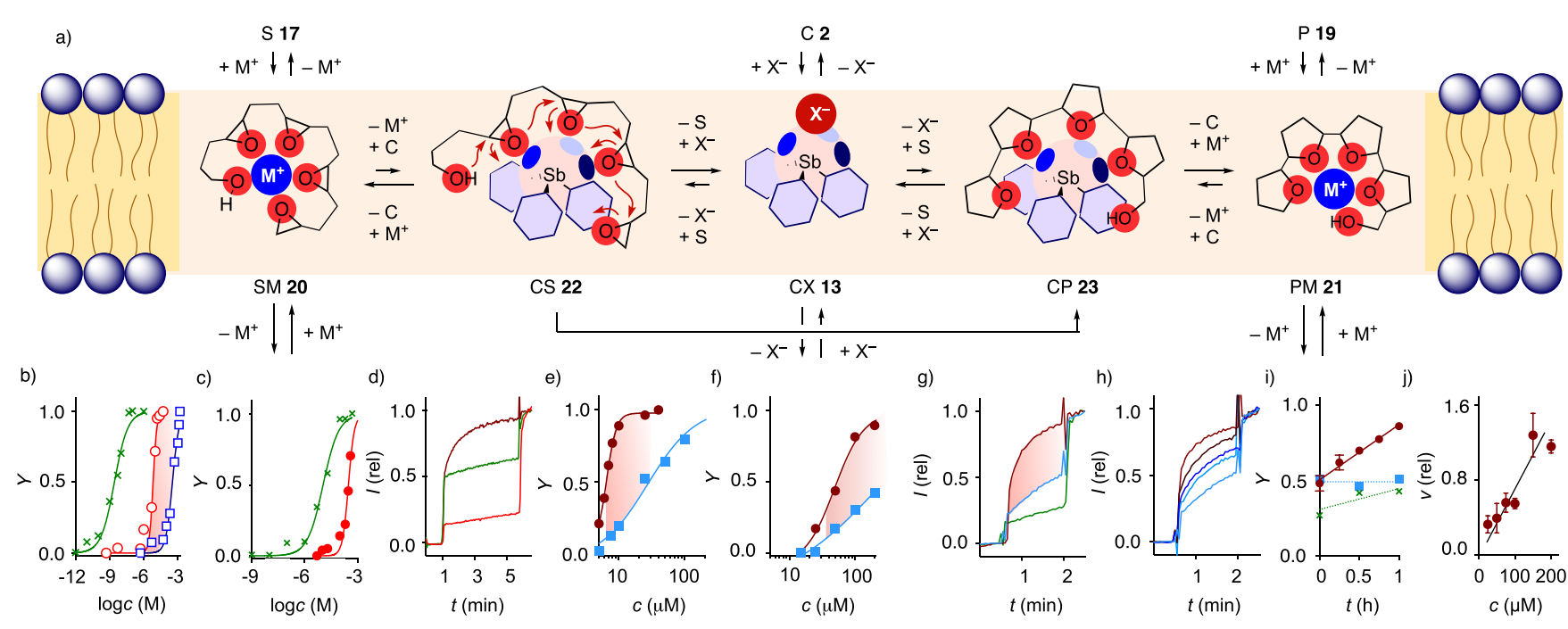

Figure 3. (a) Coupled transport and catalysis in EYPC LUVs with $\mathrm{M}^{+}$-transporting substrate 17 and product 19, $\mathrm{X}^{-}$-transporting catalyst 2, and notional structures of CS 22 and CP 23. (b-j) Selected data for transport in the HPTS assay in LUVs, $1 \mathrm{mM} \mathrm{HPTS}, 10 \mathrm{mM}$ HEPES, pH 7.0, 25 ${ }^{\circ} \mathrm{C}$; (b-e) $125 \mu \mathrm{M},(\mathrm{f}-\mathrm{j}) 500 \mu \mathrm{M}$ EYPC; (b) $100 \mathrm{mM} \mathrm{NaCl},(\mathrm{c}-\mathrm{j}) 67 \mathrm{mM} \mathrm{Na}_{2} \mathrm{SO}_{4}$. (b) DRCs for 17 (squares), 2 (crosses), and 19 (circles) in buffer with $\mathrm{NaCl}$. (c) DRCs for 2 (crosses) and 19 (circles) in buffer with $\mathrm{Na}_{2} \mathrm{SO}_{4}$. (d) Change in emission $I$ of HPTS $\left(\lambda_{\text {em }}=510 \mathrm{~nm} ; \lambda_{\text {exl }}=404\right.$ $\left.\mathrm{nm}, \lambda_{\mathrm{ex} 2}=454 \mathrm{~nm}\right)$ during the addition of $2(20 \mu \mathrm{M}$, green), $19(20 \mu \mathrm{M}$, red), and both (ruby, $t=0 \mathrm{~min}), \mathrm{NaOH}(5 \mathrm{mM}, t=1 \mathrm{~min})$, and gramicidin D (10 nM, $t=5.8 \mathrm{~min}$ ) to EYPC LUVs. (e,f) DRCs for 17 (cyan) and 19 (ruby) with (e) $20 \mu \mathrm{M} \mathrm{2,} 125 \mu \mathrm{M}$ EYPC and (f) $100 \mu \mathrm{M} \mathrm{2,}$ $500 \mu \mathrm{M}$ EYPC. (g) Change in I upon addition of $2(100 \mu \mathrm{M}$, green), together with $17(100 \mu \mathrm{M}$, cyan) and $19(100 \mu \mathrm{M}, \mathrm{ruby}, t=0 \mathrm{~min}), \mathrm{NaOH}(t$ $=0.5 \mathrm{~min})$, and gramicidin $\mathrm{D}\left(t=2 \mathrm{~min} ; 500 \mu \mathrm{M} \mathrm{EYPC}, 67 \mathrm{mM} \mathrm{Na}_{2} \mathrm{SO}_{4}\right)$. (h) Change in $I$ during the addition of $\mathrm{NaOH}(t=0.5 \mathrm{~min})$ and gramicidin $\mathrm{D}(t=2 \mathrm{~min})$ measured $t=0$ (cyan), 15,30,45, and $60 \mathrm{~min}$ (ruby) after the addition of $17(100 \mu \mathrm{M})$ and $2(100 \mu \mathrm{M})$. (i) $Y$ as a function of the reaction time $t$ for $2(100 \mu \mathrm{M}$, green), 17 (100 $\mu \mathrm{M}$, cyan; activities were recorded with $100 \mu \mathrm{M} 2$, added right before the measurements), and both together (ruby, mean \pm standard deviation of three experiments). (j) Initial velocity $v$ (best fit \pm error) of changes in $Y$ as a function of the concentration of 17 at constant $2(100 \mu \mathrm{M})$, measured as in $(\mathrm{g})-(\mathrm{i})$ for varied substrate concentrations.

The replacement of the chloride anions in the buffer by sulfates, which are more difficult to dehydrate and transport, solved this problem: The $\mathrm{EC}_{50}$ of 2 increased almost 1000 times to $\mathrm{EC}_{50}=14 \pm 3 \mu \mathrm{M}$ (Figures $3 \mathrm{c}$ and 1 ).

Original HPTS kinetics under these conditions for $\mathbf{2}$ at the most sensitive 50\% activity (green), 19 at minimal detectable activity (red), and both transporting together (ruby) revealed that their activities were overadditive (Figure 3d). Similar overadditivity was found for 2 and 17 (Figure S23). Cooperativity rather than anticooperativity demonstrated that the transporter-ion complexes 20, 21, and 13 are more stable than catalyst-substrate (CS) complex 22 and CP 23 (Figure 3a). Such less stable CS and CP are beneficial to avoid anticatalysis and product inhibition.

In the presence of $20 \mu \mathrm{M} \mathrm{2}$, the differences in transport activity between 17 and 19 were well preserved (Figure 3e, Hill coefficients $n>1$ especially for 19 suggested that PM 21 might be a 2:1 complex, Tables S3 and S4). To stabilize the system and access higher concentrations for faster conversion, the lipid concentration was increased. With four times more vesicles and $100 \mu \mathrm{M} \mathrm{2}$, the transport activities of $17\left(\mathrm{EC}_{50}=\right.$ $200 \pm 75 \mu \mathrm{M})$ and $19\left(\mathrm{EC}_{50}=48 \pm 7 \mu \mathrm{M}\right)$ decreased correspondingly, while the range for in situ detection of their conversion increased from 5-30 $\mu \mathrm{M}$ to $40->200 \mu \mathrm{M}$ substrate (Figure 3e,f, red areas).

Under these optimized conditions, 2 was nearly inactive (Figure 3g). The difference between 17 and 19 in the presence of 2 remained significant, promising detectability of the cyclization (Figure 3g, red area). The substrate, catalyst, and vesicles were thus mixed together under these conditions and stirred for given times before transport activity measurements. Activities increased with reaction time (Figure 3h,i). With 100 $\mu \mathrm{M}$ substrate and catalyst at $20^{\circ} \mathrm{C}$, full conversion was reached in $1 \mathrm{~h}$ (Figures $3 \mathrm{~g}, \mathrm{~h}$, ruby). Controls with either catalyst or substrate alone did not generate similar activity (Figure 3i). Repetition at different substrate and constant catalyst concentrations gave the expected changes in initial velocity (Figure 3j).

Cyclization of $2.0 \mathrm{M}$ monoepoxide with $100 \mathrm{~mol} \%$ stibine 2 in $\mathrm{CD}_{2} \mathrm{Cl}_{2}$ takes $48 \mathrm{~h}$ at $40{ }^{\circ} \mathrm{C}^{44}$ When reacted at $1.0 \mathrm{M}$ concentrations for 4 days, tetra-epoxide $\mathbf{1 7}$ was fully converted into 19 (Figure S25). Comparison of $1.0 \mathrm{M}$ substrate converted in $96 \mathrm{~h}$ at $40{ }^{\circ} \mathrm{C}$ with $100 \mu \mathrm{M}$ substrate converted in $1 \mathrm{~h}$ at $20^{\circ} \mathrm{C}$, also considering the van't Hoff equation, implied a rate enhancement beyond 6 orders of magnitude. Based on the lipid concentrations used, the high local concentration in membranes can only account for about $10^{3}$ fold increases in rate. The found rate enhancement was thus significant, possibly reflecting a shift from more stepwise to more concerted cascade cyclizations.

In summary, we introduce an operational system that combines catalysis and transport in lipid bilayer membranes, with synergistic anion and cation transporters realizing pnictogen-bonding catalysis under conditions that do not work in bulk solution. With the methods in place, these results provide a solid basis to exploit the many aspects of lipid bilayer membranes as a unique, directionally accessible, solvent-free, and structured nanospace for translocation-coupled molecular transformation.

\section{ASSOCIATED CONTENT}

\section{Supporting Information}

The Supporting Information is available free of charge at https://pubs.acs.org/doi/10.1021/jacsau.1c00345. 
Detailed experimental procedures, materials and methods, compound synthesis and characterization, original fluorescence kinetics traces, dose-response curves, Hill analyses, data summarizing tables (PDF)

\section{AUTHOR INFORMATION}

\section{Corresponding Author}

Stefan Matile - Department of Organic Chemistry, University of Geneva, 1211 Geneva, Switzerland; (1) orcid.org/00000002-8537-8349; Email: stefan.matile@unige.ch

\section{Authors}

Heorhii V. Humeniuk - Department of Organic Chemistry, University of Geneva, 1211 Geneva, Switzerland

Andrea Gini - Department of Organic Chemistry, University of Geneva, 1211 Geneva, Switzerland

Xiaoyu Hao - Department of Organic Chemistry, University of Geneva, 1211 Geneva, Switzerland; Present

Address: Chengdu University of Technology, Chengdu, People's Republic of China

Filipe Coelho - Department of Organic Chemistry, University of Geneva, 1211 Geneva, Switzerland

Naomi Sakai - Department of Organic Chemistry, University of Geneva, 1211 Geneva, Switzerland; 이이.org/00000002-9460-1944

Complete contact information is available at: https://pubs.acs.org/10.1021/jacsau.1c00345

\section{Author Contributions}

${ }^{\dagger}$ H.V.H. and A.G. contributed equally.

Notes

The authors declare no competing financial interest.

\section{ACKNOWLEDGMENTS}

We thank Q. Laurent for assistance with synthesis, the NMR and MS platforms for services, and the University of Geneva, the National Centre for Competence in Research (NCCR) Molecular Systems Engineering, the NCCR Chemical Biology, and the Swiss NSF for financial support.

\section{REFERENCES}

(1) Schenning, A.; Lutje Spelberg, J.; Driessen, M.; Hauser, M.; Feiters, M.; Nolte, R. Enzyme Mimic Displaying Oscillatory Behavior. Oscillating Reduction of Manganese(III) Porphyrin in a MembraneBound Cytochrome P-450 Model System. J. Am. Chem. Soc. 1995, 117, 12655-12656.

(2) Luisi, P. L.; Walde, P.; Oberholzer, T. Lipid Vesicles as Possible Intermediates in the Origin of Life. Curr. Opin. Colloid Interface Sci. 1999, 4, 33-39.

(3) Sadownik, A.; Stefely, J.; Regen, S. L. Polymerized Liposomes Formed under Extremely Mild Conditions. J. Am. Chem. Soc. 1986, 108, 7789-7791.

(4) Ringsdorf, H.; Schlarb, B.; Venzmer, J. Molecular Architecture and Function of Polymeric Oriented Systems: Models for the Study of Organization, Surface Recognition, and Dynamics of Biomembranes. Angew. Chem. Int. Ed. 1988, 27, 113-158.

(5) Kolusheva, S.; Molt, O.; Herm, M.; Schrader, T.; Jelinek, R. Selective Detection of Catecholamines by Synthetic Receptors Embedded in Chromatic Polydiacetylene Vesicles. J. Am. Chem. Soc. 2005, 127, 10000-10001.

(6) Grimaldi, J. J.; Boileau, S.; Lehn, J.-M. Light-Driven, CarrierMediated Electron Transfer across Artificial Membranes. Nature 1977, 265, 229-230.
(7) Gust, D.; Moore, T. A.; Moore, A. L. Mimicking Photosynthetic Solar Energy Transduction. Acc. Chem. Res. 2001, 34, 40-48.

(8) Perez-Velasco, A.; Gorteau, V.; Matile, S. Rigid Oligoperylenediimide Rods: Anion- $\pi$ Slides with Photosynthetic Activity. Angew. Chem., Int. Ed. 2008, 47, 921-923.

(9) Pannwitz, A.; Klein, D. M.; Rodríguez-Jiménez, S.; Casadevall, C.; Song, H.; Reisner, E.; Hammarström, L.; Bonnet, S. Roadmap towards Solar Fuel Synthesis at the Water Interface of Liposome Membranes. Chem. Soc. Rev. 2021, 50, 4833-4855.

(10) Baumeister, B.; Sakai, N.; Matile, S. p-Octiphenyl $\beta$-Barrels with Ion Channel and Esterase Activity. Org. Lett. 2001, 3, 4229-4232.

(11) Bravin, C.; Hunter, C. A. Template Effects of Vesicles in Dynamic Covalent Chemistry. Chem. Sci. 2020, 11, 9122-9125.

(12) Sakai, N.; Matile, S. Conjugated Polyimine Dynamers as PhaseSensitive Membrane Probes. J. Am. Chem. Soc. 2018, 140, 1143811443.

(13) Wilson, D. A.; Nolte, R. J. M.; van Hest, J. C. M. Autonomous Movement of Platinum-Loaded Stomatocytes. Nat. Chem. 2012, 4 , $268-274$.

(14) Peters, R. J. R. W.; Marguet, M.; Marais, S.; Fraaije, M. W.; van Hest, J. C. M.; Lecommandoux, S. Cascade Reactions in Multicompartmentalized Polymersomes. Angew. Chem., Int. Ed. 2014, 53, 146-150.

(15) Belluati, A.; Thamboo, S.; Najer, A.; Maffeis, V.; Planta, C.; von Craciun, I.; Palivan, C. G.; Meier, W. Multicompartment Polymer Vesicles with Artificial Organelles for Signal-Triggered Cascade Reactions Including Cytoskeleton Formation. Adv. Funct. Mater. 2020, 30, 2002949.

(16) Trevisan, L.; Kocsis, I.; Hunter, C. A. Redox Switching of an Artificial Transmembrane Signal Transduction System. Chem. Commun. 2021, 57, 2196-2198.

(17) De Poli, M.; Zawodny, W.; Quinonero, O.; Lorch, M.; Webb, S. J.; Clayden, J. Conformational Photoswitching of a Synthetic Peptide Foldamer Bound within a Phospholipid Bilayer. Science 2016, 352, 575-580.

(18) Bickerton, L. E.; Johnson, T. G.; Kerckhoffs, A.; Langton, M. J. Supramolecular Chemistry in Lipid Bilayer Membranes. Chem. Sci. 2021, 12, 11252-11274.

(19) Qing, Y.; Liu, M. D.; Hartmann, D.; Zhou, L.; Ramsay, W. J.; Bayley, H. Single-Molecule Observation of Intermediates in Bioorthogonal 2-Cyanobenzothiazole Chemistry. Angew. Chem., Int. Ed. 2020, 59, 15711-15716.

(20) Pavlick, R. A.; Dey, K. K.; Sirjoosingh, A.; Benesi, A.; Sen, A. A Catalytically Driven Organometallic Molecular Motor. Nanoscale 2013, 5, 1301-1304.

(21) Zhang, Y.; Hess, H. Enhanced Diffusion of Catalytically Active Enzymes. ACS Cent. Sci. 2019, 5, 939-948.

(22) Wang, H.; Park, M.; Dong, R.; Kim, J.; Cho, Y.-K.; Tlusty, T.; Granick, S. Boosted Molecular Mobility during Common Chemical Reactions. Science 2020, 369, 537-541.

(23) Sakai, N.; Sordé, N.; Matile, S. Synthetic Catalytic Pores. J. Am. Chem. Soc. 2003, 125, 7776-7777.

(24) Davis, J. T.; Gale, P. A.; Quesada, R. Advances in Anion Transport and Supramolecular Medicinal Chemistry. Chem. Soc. Rev. 2020, 49, 6056-6086.

(25) Huang, W.-L.; Wang, X.-D.; Ao, Y.-F.; Wang, Q.-Q.; Wang, D.$X$. Artificial Chloride-Selective Channel: Shape and Function Mimic of the ClC Channel Selective Pore. J. Am. Chem. Soc. 2020, 142, 13273-13277.

(26) August, D. P.; Borsley, S.; Cockroft, S. L.; della Sala, F.; Leigh, D. A.; Webb, S. J. Transmembrane Ion Channels Formed by a Star of David [2]Catenane and a Molecular Pentafoil Knot. J. Am. Chem. Soc. 2020, 142, 18859-18865.

(27) Martinez-Crespo, L.; Hewitt, S. H.; De Simone, N. A.; Sindelar, V.; Davis, A. P.; Butler, S.; Valkenier, H. Transmembrane Transport of Bicarbonate Unravelled. Chem. Eur. J. 2021, 27, 7320.

(28) Saha, T.; Dasari, S.; Tewari, D.; Prathap, A.; Sureshan, K. M.; Bera, A. K.; Mukherjee, A.; Talukdar, P. Hopping-Mediated Anion 
Transport through a Mannitol-Based Rosette Ion Channel. J. Am. Chem. Soc. 2014, 136, 14128-14135.

(29) Marshall, S. R.; Singh, A.; Wagner, J. N.; Busschaert, N. Enhancing the Selectivity of Optical Sensors Using Synthetic Transmembrane Ion Transporters. Chem. Commun. 2020, 56, 14455-14458.

(30) Wu, X.; Small, J. R.; Cataldo, A.; Withecombe, A. M.; Turner, P.; Gale, P. A. Voltage-Switchable HCl Transport Enabled by Lipid Headgroup-Transporter Interactions. Angew. Chem., Int. Ed. 2019, 58, 15142-15147.

(31) Lee, L. M.; Tsemperouli, M.; Poblador-Bahamonde, A. I.; Benz, S.; Sakai, N.; Sugihara, K.; Matile, S. Anion Transport with Pnictogen Bonds in Direct Comparison with Chalcogen and Halogen Bonds. J. Am. Chem. Soc. 2019, 141, 810-814.

(32) Park, G.; Brock, D. J.; Pellois, J.-P.; Gabbaï, F. P. Heavy Pnictogenium Cations as Transmembrane Anion Transporters in Vesicles and Erythrocytes. Chem 2019, 5, 2215-2227.

(33) Park, G.; Gabbaï, F. P. Redox-Controlled Chalcogen and Pnictogen Bonding: The Case of a Sulfonium/Stibonium Dication as a Preanionophore for Chloride Anion Transport. Chem. Sci. 2020, 11, 10107-10112.

(34) Benz, S.; Macchione, M.; Verolet, Q.; Mareda, J.; Sakai, N.; Matile, S. Anion Transport with Chalcogen Bonds. J. Am. Chem. Soc. 2016, 138, 9093-9096.

(35) Bickerton, L. E.; Docker, A.; Sterling, A. J.; Kuhn, H.; Duarte, F.; Beer, P. D.; Langton, M. J. Highly Active Halogen Bonding and Chalcogen Bonding Chloride Transporters with Non-Protonophoric Activity. Chem. Eur. J. 2021, 27, 11738-11745.

(36) Vargas Jentzsch, A.; Matile, S. Transmembrane HalogenBonding Cascades. J. Am. Chem. Soc. 2013, 135, 5302-5303.

(37) Ren, C.; Ding, X.; Roy, A.; Shen, J.; Zhou, S.; Chen, F.; Li, S. F. Y.; Ren, H.; Yang, Y. Y.; Zeng, H. A Halogen Bond-Mediated Highly Active Artificial Chloride Channel with High Anticancer Activity. Chem. Sci. 2018, 9, 4044-4051.

(38) Benz, S.; Poblador-Bahamonde, A. I.; Low-Ders, N.; Matile, S. Catalysis with Pnictogen, Chalcogen, and Halogen Bonds. Angew. Chem., Int. Ed. 2018, 57, 5408-5412.

(39) Yang, M.; Tofan, D.; Chen, C.-H.; Jack, K. M.; Gabbaï, F. P. Digging the Sigma-Hole of Organoantimony Lewis Acids by Oxidation. Angew. Chem., Int. Ed. 2018, 57, 13868-13872.

(40) Zhang, J.; Wei, J.; Ding, W.-Y.; Li, S.; Xiang, S.-H.; Tan, B. Asymmetric Pnictogen-Bonding Catalysis: Transfer Hydrogenation by a Chiral Antimony(V) Cation/Anion Pair. J. Am. Chem. Soc. 2021, 143, 6382-6387.

(41) Moaven, S.; Yu, J.; Vega, M.; Unruh, D. K.; Cozzolino, A. F. Self-Assembled Reversed Bilayers Directed by Pnictogen Bonding to Form Vesicles in Solution. Chem. Commun. 2018, 54, 8849-8852.

(42) Scheiner, S. The Pnicogen Bond: Its Relation to Hydrogen, Halogen, and Other Noncovalent Bonds. Acc. Chem. Res. 2013, 46, 280-288.

(43) Paraja, M.; Gini, A.; Sakai, N.; Matile, S. Pnictogen-Bonding Catalysis: An Interactive Tool to Uncover Unorthodox Mechanisms in Polyether Cascade Cyclizations. Chem. Eur. J. 2020, 26, 1547115476.

(44) Gini, A.; Paraja, M.; Galmés, B.; Besnard, C.; PobladorBahamonde, A. I.; Sakai, N.; Frontera, A.; Matile, S. PnictogenBonding Catalysis: Brevetoxin-Type Polyether Cyclizations. Chem. Sci. 2020, 11, 7086-7091.

(45) Taylor, M. S. Anion Recognition Based on Halogen, Chalcogen, Pnictogen and Tetrel Bonding. Coord. Chem. Rev. 2020, 413, 213270.

(46) Bauzá, A.; Mooibroek, T. J.; Frontera, A. The Bright Future of Unconventional $\sigma / \pi$-Hole Interactions. ChemPhysChem 2015, 16, 2496-2517.

(47) Biot, N.; Bonifazi, D. Chalcogen-Bond Driven Molecular Recognition at Work. Coord. Chem. Rev. 2020, 413, 213243.

(48) Vogel, L.; Wonner, P.; Huber, S. M. Chalcogen Bonding: An Overview. Angew. Chem., Int. Ed. 2019, 58, 1880-1891.
(49) Cavallo, G.; Metrangolo, P.; Milani, R.; Pilati, T.; Priimagi, A.; Resnati, G.; Terraneo, G. The Halogen Bond. Chem. Rev. 2016, 116, $2478-2601$

(50) Lim, J. Y. C.; Beer, P. D. Sigma-Hole Interactions in Anion Recognition. Chem. 2018, 4, 731-783.

(51) Breugst, M.; Koenig, J. J. $\sigma$-Hole Interactions in Catalysis. Eur. J. Org. Chem. 2020, 2020, 5473-5487.

(52) Weiss, R.; Aubert, E.; Pale, P.; Mamane, V. Chalcogen-Bonding Catalysis with Telluronium Cations. Angew. Chem., Int. Ed. 2021, 60, 19281-19286.

(53) Wang, W.; Zhu, H.; Liu, S.; Zhao, Z.; Zhang, L.; Hao, J.; Wang, Y. Chalcogen-Chalcogen Bonding Catalysis Enables Assembly of Discrete Molecules. J. Am. Chem. Soc. 2019, 141, 9175-9179.

(54) Riwar, L.-J.; Trapp, N.; Root, K.; Zenobi, R.; Diederich, F. Supramolecular Capsules: Strong versus Weak Chalcogen Bonding. Angew. Chem., Int. Ed. 2018, 57, 17259-17264.

(55) Beno, B. R.; Yeung, K.-S.; Bartberger, M. D.; Pennington, L. D.; Meanwell, N. A. A Survey of the Role of Noncovalent Sulfur Interactions in Drug Design. J. Med. Chem. 2015, 58, 4383-4438.

(56) Gleiter, R.; Haberhauer, G.; Werz, D. B.; Rominger, F.; Bleiholder, C. From Noncovalent Chalcogen-Chalcogen Interactions to Supramolecular Aggregates: Experiments and Calculations. Chem. Rev. 2018, 118, 2010-2041.

(57) Matile, S.; Sakai, N.; Hennig, A. Transport Experiments in Membranes. In Techniques; Supramolecular Chemistry: From Molecules to Nanomaterials; Steed, J. W., Gale, P. A., Eds.; John Wiley \& Sons Ltd: Chichester UK, 2012; Vol. 2, pp 473-500.

(58) Wu, X.; Howe, E. N. W.; Gale, P. A. Supramolecular Transmembrane Anion Transport: New Assays and Insights. Acc. Chem. Res. 2018, 51, 1870-1879.

(59) Wagner, H.; Harms, K.; Koert, U.; Meder, S.; Boheim, G. Oligo-THF Peptides: Synthesis, Membrane Insertion, and Studies of Ion Channel Activity. Angew. Chem., Int. Ed. 1996, 35, 2643-2646.

(60) Gokel, G. W.; Negin, S. Synthetic Ion Channels: From Pores to Biological Applications. Acc. Chem. Res. 2013, 46, 2824-2833.

(61) Carmichael, V. E.; Dutton, P. J.; Fyles, T. M.; James, T. D.; Swan, J. A.; Zojaji, M. Biomimetic Ion Transport: A Functional Model of a Unimolecular Ion Channel. J. Am. Chem. Soc. 1989, 111, 767769.

(62) Otis, F.; Auger, M.; Voyer, N. Exploiting Peptide Nanostructures to Construct Functional Artificial Ion Channels. Acc. Chem. Res. 2013, 46, 2934-2943.

(63) Zheng, S.-P.; Huang, L.-B.; Sun, Z.; Barboiu, M. Self-Assembled Artificial Ion-Channels toward Natural Selection of Functions. Angew. Chem., Int. Ed. 2021, 60, 566-597.

(64) Yan, Z.-J.; Wang, D.; Ye, Z.; Fan, T.; Wu, G.; Deng, L.; Yang, L.; Li, B.; Liu, J.; Ma, T.; Dong, C.; Li, Z.-T.; Xiao, L.; Wang, Y.; Wang, W.; Hou, J.-L. Artificial Aquaporin That Restores Wound Healing of Impaired Cells. J. Am. Chem. Soc. 2020, 142, 1563815643.

(65) Muraoka, T.; Umetsu, K.; Tabata, K. V.; Hamada, T.; Noji, H.; Yamashita, T.; Kinbara, K. Mechano-Sensitive Synthetic Ion Channels. J. Am. Chem. Soc. 2017, 139, 18016-18023.

(66) Liu, H.; Lin, S.; Jacobsen, K. M.; Poulsen, T. B. Chemical Syntheses and Chemical Biology of Carboxyl Polyether Ionophores: Recent Highlights. Angew. Chem., Int. Ed. 2019, 58, 13630-13642.

(67) Vilotijevic, I.; Jamison, T. F. Epoxide-Opening Cascades in the Synthesis of Polycyclic Polyether Natural Products. Angew. Chem., Int. Ed. 2009, 48, 5250-5281.

(68) Sittihan, S.; Jamison, T. F. Total Synthesis of the Marine Ladder Polyether Gymnocin B. J. Am. Chem. Soc. 2019, 141, 1123911244.

(69) Li, F.-X.; Ren, S.-J.; Li, P.-F.; Yang, P.; Qu, J. Endo-Selective Epoxide-Opening Cascade for Fast Assembly of the Polycyclic Core Structure of Marine Ladder Polyethers. Angew. Chem., Int. Ed. 2020, 59, $18473-18478$

(70) Pinacho Crisóstomo, F. R.; Lledó, A.; Shenoy, S. R.; Iwasawa, T.; Rebek, J. Recognition and Organocatalysis with a Synthetic Cavitand Receptor. J. Am. Chem. Soc. 2009, 131, 7402-7410. 
(71) Valentine, J. C.; McDonald, F. E.; Neiwert, W. A.; Hardcastle, K. I. Biomimetic Synthesis of Trans,Syn,Trans-Fused Polyoxepanes: Remarkable Substituent Effects on the Endo-Regioselective Oxacyclization of Polyepoxides. J. Am. Chem. Soc. 2005, 127, 4586-4587.

(72) Paraja, M.; Hao, X.; Matile, S. Polyether Natural Product Inspired Cascade Cyclizations: Autocatalysis on $\pi$-Acidic Aromatic Surfaces. Angew. Chem., Int. Ed. 2020, 59, 15093-15097.

(73) Paraja, M.; Matile, S. Primary Anion- $\pi$ Catalysis of EpoxideOpening Ether Cyclization into Rings of Different Sizes: Access to New Reactivity. Angew. Chem., Int. Ed. 2020, 59, 6273-6277.

(74) Hao, X.; Li, T.-R.; Chen, H.; Gini, A.; Zhang, X.; Rosset, S.; Mazet, C.; Tiefenbacher, K.; Matile, S. Bioinspired Ether Cyclizations within a $\pi$-Basic Capsule Compared to Autocatalysis on $\pi$-Acidic Surfaces and Pnictogen-Bonding Catalysts. Chem. Eur. J. 2021, 27, $12215-12223$. 